\title{
Comparação da Estabilidade do Arco e da Variabilidade da Geometria de Soldas Obtidas pelos Processos MIG/MAG e Arame Tubular
}

\author{
Romário Mauricio Urbanetto Nogueira ${ }^{1}$, Carlos Enrique Niño Bohórquez ${ }^{2}$, Igor Giacomelli Zanella ${ }^{1}$ \\ 1 Colégio Técnico Industrial, Universidade Federal de Santa Maria - UFSM, Santa Maria, RS, Brasil. \\ 2 Laboratório de Soldagem, Departamento de Engenharia Mecânica, Universidade Federal de Santa Catarina - UFSC, \\ Florianópolis, SC, Brasil.
}

Recebido: 19 Mar., 2015

Aceito: 17 Jun., 2015

E-mails: romario@ctism.ufsm.br (RMUN), carlos.nino@ufsc.br (CENB)
Resumo: Apesar da similaridade, os processos MIG/MAG e Eletrodo Tubular apresentam particularidades quanto à estabilidade do arco e variabilidade nas características dos cordões. Assim, a escolha de um dos processos, para aplicação específica deveria considerar como tais particularidades afetam a qualidade destas soldas. Para subsidiar esta escolha, o presente estudo teve como objetivo investigar como a mudança na corrente média afeta a estabilidade e a regularidade das transferências de metal em soldas realizadas com tensão constante e corrente pulsada e comparar a variabilidade da geometria e da diluição destas soldas. Para atingir estes objetivos foram realizadas soldas automatizadas, tendo como metal de base o aço ABNT 1020 e como metais de adição o arame AWS ER70S-6 e AWS E71T-1. Além das soldas com variação da corrente média, os testes envolveram a determinação dos parâmetros para a ocorrência de transferência estável por curto-circuito, goticular e pulsado. Os resultados mostraram que a tensão que determina a maior estabilidade na transferência pelo modo curto-circuito, independe da velocidade de soldagem e aumenta com a velocidade do arame, mostraram também que as soldas com arame tubular apresentaram maiores variabilidades comparadas ao arame maciço.

Palavras-chave: Processo MIG/MAG; Processo arame tubular; Estabilidade do arco; Variabilidade.

\section{Comparison of Arc Stability and Variability of Geometry of Welds Obtained by MIG/MAG and FCAW Processes}

\begin{abstract}
Despite the similarity, the MIG/MAG and Tubular Electrode processes have particularities regarding the arc stability and variability in the characteristics of beads. Thus, the choice of one of the processes to specific application should consider how such particularities affect the quality of these welds. To support this choice, this study aimed to investigate as change in average current affects the stability and regularity of the metal transfers on welds performed with constant voltage and current pulsed and compare the variability of geometry and dilution of these weld. To achieve these goals automated welds were carried out, based on the metal ABNT 1020 and adding the metal wire ER70S -6 AWS and AWS E71T -1. In addition to the welds with the variation current average, the tests involved the determination of the parameters for the occurrence of stable transfer by short circuit, goticular and pulsed. The results showed that the voltage that determines the greatest stability in the short circuit transfer mode, is independent the welding speed of and increases with the wire speed, also showed that tubular wire solders showed higher variability compared to the solid wire.
\end{abstract}

Key-words: MIG/MAG; Flux cored electrode process; Arc stability; Variability.

\section{Introdução}

A crescente utilização industrial dos processos MIG/MAG e Eletrodo Tubular vem ocorrendo porque estes processos, que têm sido objeto de um contínuo desenvolvimento, apresentam excelente produtividade devido à sua característica semiautomática decorrente da alimentação continua do arame eletrodo que facilita a automatização destes processos. Porém, apesar da similaridade, estes processos apresentam características específicas (não somente a própria forma do arame) que determinam uma variabilidade nas características finais dos cordões inerente a cada processo. Ainda que exista na literatura considerável número de informações sobre a aplicação desses processos de forma automatizada, em poucos estudos se procura comparar, de forma mais sistemática, a variabilidade destes processos quando as soldas são realizadas pelos diferentes modos de transferência metálica, 
o que pode representar mais um critério de escolha quando se procura decidir qual processo utilizar em uma determinada aplicação. Como por exemplo, no reparo de dutos utilizando a técnica da soldagem em operação e o método da simples deposição de solda, que apresenta como principais dificuldades a ocorrência de trincas a frio e a perfuração da parede do tubo pelo arco voltaico. Desta maneira, surge a demanda de se investigar a variabilidade inerente a estes processos em aspectos tais como a geometria do cordão (notadamente na penetração) e na diluição. A estatística descritiva, que é um ramo da estatística, aplica várias técnicas para descrever e sumarizar um conjunto de dados e, portanto, diferencia-se da estatística inferencial, ou estatística indutiva, pelo objetivo: organizar, sumarizar dados ao invés de usar os dados em aprendizado sobre a população. Na estatística descritiva algumas medidas que são normalmente usadas para descrever um conjunto de dados são medidas de tendência central e medidas de variabilidade ou dispersão. As medidas de tendência central que incluem a média nos dão uma ideia da concentração dos dados em torno de um valor. Entretanto há situações em que é necessário conhecer também suas características de espalhamento ou dispersão (medidas de variabilidade), como por exemplo, no reparo de dutos utilizando a técnica da soldagem em operação e o método da simples deposição de solda onde é importante conhecer não só o valor médio da penetração como sua dispersão. Estas medidas de variabilidade incluem a variância, o desvio padrão e o desvio padrão relativo (ou coeficiente de variação) e como apontou Montgomery [1] à medida que a variabilidade aumenta a variância também aumenta. A unidade de variância é expressa no quadrado da variável original, por exemplo, se estamos medindo tensão elétrica, a unidade da variância é (volts)². Assim, é costume utilizar a raiz quadrada da variância, chamada desvio padrão que expressa a dispersão na unidade original da variável. Mas em muitas situações o desvio padrão não nos diz muita coisa, por exemplo, um desvio padrão de duas unidades pode ser considerado pequeno para um conjunto de valores com média de duzentas unidades, no entanto, se a média for igual a vinte unidades, o mesmo não pode ser dito. Para contornar essas limitações, podemos caracterizar a variabilidade dos dados em termos relativos a seu valor médio, medida denominada desvio padrão expressa em termos percentuais. Com finalidade de facilitar a realização das soldagens e, em consequência, a estimação da qualidade das soldas, pesquisadores sempre procuram quantificar os fatores que influem sobre a estabilidade do processo. Segundo Ponomarev, apud Rezende [2], a estabilidade do processo MIG/MAG pode ser avaliada por três fatores: estabilidade do arco, regularidade da transferência metálica e comportamento operacional, os quais se relacionam de forma muito próxima. Antes avaliada apenas com base em características elementares do processo, tais como ruídos e respingos, hoje, a estabilidade, é avaliada fazendo-se uso de vários meios e técnicas. Assim, por exemplo, Mita [3] e Baixo [4] propuseram índices de regularidade compostos pelos valores médios e desvios padrão de parâmetros extraídos dos oscilogramas (tempos de arco aberto, tempos de curto-circuito, picos de corrente de curto-circuito), com menores valores do índice indicando melhor estabilidade, também observaram a existência de um ponto de inflexão a partir do qual valores crescentes ou decrescentes de tensão resultam em menor regularidade. Da mesma forma, Kang [5], ao utilizar a quantidade de respingos gerada em função da tensão para analisar a estabilidade, obteve resultados parecidos com Mita e Baixo, ou seja, existe um ponto de inflexão a partir do qual valores crescentes ou decrescentes de tensão resultam em menor estabilidade do processo de soldagem. Outro critério para avaliar a estabilidade na soldagem por curto-circuito proposto por diversos autores como, por exemplo, Den Ouden [6] e Souza [7], considera que uma maior frequência de transferência metálica indica maior estabilidade da mesma. Pois, a frequência de transferências metálicas tem uma tendência de crescer até um valor máximo quando se aumenta a tensão do arco, para depois cair continuamente para maiores valores de tensão. A explicação para esse comportamento reside em que, para elevadas tensões de arco (e, portanto, grandes comprimentos de arco), devem ser esperadas baixas frequências de transferência, pois se criam condições para a gota crescer antes de se destacar. Já para valores muito baixos de tensão (arcos muito curtos) a diminuição da frequência justifica-se pelo caráter explosivo da transferência nestas condições, o que faz com que o arco atinja comprimentos bastante longos logo em seguida de cada curto-circuito, de modo que aumenta a demora em ocorrer uma nova aproximação. Conforme Subramanian [8], os diferentes modos de transferência do metal de adição afetam a penetração, a capacidade de soldar em várias posições, a estabilidade da poça fundida e a quantidade de respingos. Desta forma, diversos pesquisadores propuseram mapas de transferência metálica, como por exemplo, o mapa de transferência metálica proposto por Kim [9] (apresentado na Figura 1), que mostra as regiões de estabilidade dos diversos modos de transferência, em função do par de valores velocidade do arame e tensão do arco. Esses mapas são válidos para certas condições de soldagem, como aquelas que constam na legenda da Figura 1. 


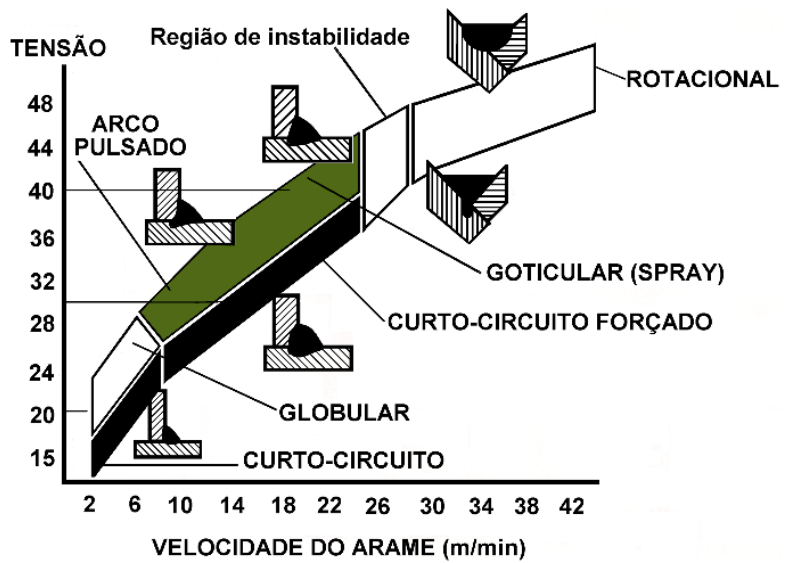

Figura 1. Mapa de transferência metálica elaborado por Kim [8] para o processo MIG/MAG, com arame de aço carbono de 1,2 mm de diâmetro e gás de proteção $\mathrm{Ar}-8 \mathrm{CO}_{2}$.

Desta maneira, os objetivos deste trabalho foram investigar como a variação na corrente média de soldagem de soldas realizadas de forma automática com os processos MIG/MAG e arame tubular em tensão constante e corrente pulsada afeta a estabilidade e a regularidade das transferências metálicas, bem como comparar a variabilidade da geometria e da diluição das soldas obtidas pelos dois processos.

\section{Materiais e Métodos}

\subsection{Aspectos gerais dos experimentos}

As soldas deste trabalho foram realizadas com simples deposição sobre chapa, tendo como metal de base o aço carbono ABNT 1020 (peças retangulares de $40 \mathrm{~mm}$ de largura, $120 \mathrm{~mm}$ comprimento e $15 \mathrm{~mm}$ de espessura), e metais de adição o arame maciço de aço carbono AWS ER70S-6 e o arame tubular rutílico AWS E71T-1, ambos com diâmetro 1,2 mm. Foi definido como parâmetros fixos (para ambos os processos) o gás de proteção Argônio $+25 \%$ $\mathrm{CO}_{2}$ com vazão de $15 \mathrm{l} / \mathrm{min}$, a polaridade CC+ e o ângulo de ataque da tocha, de $90^{\circ}$. Os equipamentos utilizados foram fonte multiprocesso da Marca IMC modelo DIGIPLUS A7, máquina de corte portátil (tartaruga) marca WHITE MARTINS modelo MC 46 para deslocamento da tocha. Para a monitoração e coleta de dados durante as soldagens foi utilizado o Sistema de Aquisição Portátil SAP 4.0 (da IMC Soldagem), composto de sensores para medir os sinais instantâneos de corrente, tensão, velocidade de arame, vazão de gás de soldagem e por um software de aquisição e análise destes sinais. Para atingir os objetivos propostos neste estudo foi necessário realizar as seguintes etapas: determinação dos parâmetros para ocorrência de transferência estável pelos modos de transferência metálica por curto-circuito, goticular e pulsado; determinação da variabilidade da diluição e geometria dos cordões de solda e, finalmente, comparação da variabilidade na geometria e na diluição das soldas realizadas com os dois processos.

\subsection{Determinação dos parâmetros para ocorrência de transferência estável pelo modo curto-circuito}

A determinação dos parâmetros para a ocorrência de transferência metálica estável por curto-circuito envolveu as seguintes etapas: determinação das correntes de soldagem, investigação da influência da tensão versus indutância e determinação das tensões. As correntes utilizadas para os ensaios com transferência metálica por curto-circuito, selecionadas com base no mapa da Figura 1, foram definidas por dois valores extremos (100 e $180 \mathrm{~A}$ ), e um valor intermediário (140A). Como na transferência por curto-circuito a fonte é operada no modo tensão constante foi necessário inicialmente realizar soldas com várias velocidades do arame até conseguir as correntes desejadas. Nesses ensaios foi utilizada uma distância bico de contato peça (DBCP) de $12 \mathrm{~mm}$, o efeito indutivo ajustado no valor médio (50) da escala de regulagem da fonte e a velocidade de soldagem de $300 \mathrm{~mm} / \mathrm{min}$ (pois as soldas realizadas sobre os corpos de prova de $120 \mathrm{~mm}$ comprimento permitiram um tempo de aquisição de sinais elétricos de soldagem de pelo menos 20 s entre a abertura e fechamento do arco, ou seja, de soldagem em regime). Os valores das tensões a serem ajustadas na fonte, Uaj, foram arbitrados com base no mapa da Figura 1. 
Desta maneira, para a corrente de soldagem de 100 A utilizou-se Uaj de $18 \mathrm{~V}$ e para correntes de 140 e $180 \mathrm{~A}$ utilizou-se Uaj de 20 V. Após, com a finalidade de investigar a influência da tensão e da indutância na variação da estabilidade ao soldar com transferência por curto-circuito foram realizados ensaios (soldas) com as condições de soldagem resultante da combinação das três velocidades de soldagem que determinaram as correntes desejadas, três níveis de tensão ajustadas (arbitradas a partir do mapa da Figura 1) e três níveis de efeito indutivo, totalizando 27 ensaios. Para analisar estes ensaios foram examinados visualmente os oscilogramas de tensão e corrente e a aparência dos cordões de solda. Estas análises incluíram ainda a determinação da variabilidade da geometria e da diluição dos cordões de solda realizados nestes ensaios (utilizando a metodologia explicitada no item 2.5) e o cálculo da variabilidade da transferência, considerando dois índices, a saber, desvio padrão relativo dos picos de corrente e desvio padrão relativo dos períodos de transferência metálica, para os quais foram utilizados os sinais de tensão e corrente registrados mediante o sistema de aquisição de dados SAP 4, durante um intervalo de tempo de $10 \mathrm{~s}$ da solda em regime. Finalmente, para determinar a faixa de tensões onde ocorre transferência metálica por curto-circuito bem como a tensão em que ocorre maior estabilidade do arco e/ou regularidade da transferência metálica, foram realizados ensaios de iso-consumo (soldas com velocidade de arame constante) com as velocidades de arame que determinaram as correntes desejadas (respectivamente 2,4; 3,2 e 4,3 m/min). Para o ajuste da indutância utilizou-se o valor médio do efeito indutivo da fonte de soldagem $(\mathrm{Ks}=\mathrm{Kd}=50)$, pois, conforme indicaram os resultados da investigação da influência da tensão e indutância, as soldas realizadas com esse valor do efeito indutivo apresentaram em geral uma transferência mais regular. Após foram realizadas análises destas soldas considerando os oscilogramas de tensão e corrente, a variabilidade dos picos de corrente, a variabilidade dos períodos de transferência, bem como a frequência das transferências metálicas. As frequências de transferência metálica foram determinadas (calculadas) a partir do numero de picos de corrente registrados, com o sistema de aquisição de dados (SAP 4), durante a realização das soldas.

\subsection{Determinação dos parâmetros para ocorrência de transferência estável pelo modo goticular}

Nos ensaios para determinar os parâmetros para a ocorrência de transferência metálica estável pelo modo goticular foi utilizada uma DBCP de $12 \mathrm{~mm}$ e a velocidade de soldagem de $300 \mathrm{~mm} / \mathrm{min}$. Os ensaios foram realizados em duas etapas, uma para a determinação das correntes de soldagem e outra para a determinação das tensões. Os valores das correntes de soldagem para os ensaios com transferência goticular foram definidos por dois extremos (selecionados com base no mapa da Figura 1) e um valor intermediário. Desta forma, foram definidas as correntes de soldagem de 280, 320 e 340 A. Como para a transferência goticular a fonte também é operada no modo tensão constante, inicialmente foram realizadas soldas em que se ajustou na fonte uma tensão de $30 \mathrm{~V}$ (arbitrada com base no mapa da Figura 1) e aumentou-se a velocidade do arame gradativamente, a fim de determinar as velocidades necessárias para obter as correntes desejadas. Entretanto, como para esta tensão e as velocidades de arame ajustadas para obter correntes de 280, 320 e 340 A não ocorreu transferência pelo modo goticular devido provavelmente ao fato de este valor de tensão ser suficiente para uma transferência goticular ao utilizar como gás de proteção uma mistura com menor percentual de $\mathrm{CO}_{2}$, como por exemplo, nas soldas realizadas com gás de proteção $\mathrm{Ar}-8 \mathrm{CO}_{2}$ (vide mapa da Figura 1), mas não ser suficiente para uma transferência pelo modo goticular ao utilizar o gás de proteção $\mathrm{Ar}-25 \mathrm{CO}_{2}$. Desta maneira foi então necessário realizar ensaios de iso-consumo utilizando as velocidades de arame 8,$5 ; 9,5$ e $10 \mathrm{~m} / \mathrm{min}$, escolhidas com base nos ensaios anteriores.

\subsection{Determinação dos parâmetros para ocorrência de transferência estável pelo modo pulsado}

Conforme a literatura, o cálculo dos parâmetros para a ocorrência de transferência metálica estável pelo modo pulsado para uma dada corrente média de soldagem segue uma sequência comum que pode ser resumida nas seguintes etapas:

- Selecionar uma corrente de pulso (Ip) acima da corrente de transição;

- Determinar o tempo de pulso a partir da relação $I p^{2} t p=D$, sendo tp o tempo de pulso e $D$ a constante de destacamento, válida para um diâmetro de gota especifico. Para este trabalho foi arbitrado um valor $\mathrm{D}=500$, com base no trabalho de Motta [10]. 
- Usar equação ou gráfico que relacione a velocidade de arame (Va) com a corrente média (Im). Neste trabalho utilizou-se a Equação 1;

$\mathrm{Va}=\mathrm{K} \cdot \operatorname{Im}(1)$

sendo K uma constante determinada experimentalmente.

- Calcular o período de onda (T) da corrente pulsada, necessário para obter certo diâmetro de gota, dg, quando se utiliza certa velocidade de arame e diâmetro de eletrodo. A equação para realizar esse cálculo é derivada da relação que existe entre o volume de arame que avança durante um período de tempo e o volume da gota que será formada:

$$
T=\frac{40 . d_{g}^{3}}{v_{a} d_{e}^{2}}
$$

sendo $\mathrm{d}_{\mathrm{g}}$ o diâmetro da gota ( $\mathrm{mm}$ ) e $\mathrm{d}_{\mathrm{e}}$ o diâmetro do eletrodo (em $\mathrm{mm}$ ).

Experimentos realizados no LABSOLDA indicam que a escolha do diâmetro da gota com valor $20 \%$ acima do diâmetro do arame satisfaz a maioria das aplicações, desta forma utilizou um $\mathrm{d}_{\mathrm{g}}$ de $1,44 \mathrm{~mm}$, ou seja, com valor $20 \%$ maior que o $d_{e}$ utilizado.

- Determinar o tempo de base (tb), sabendo que $T=t b+t p$.

- Calcular a corrente de base (Ib), que permita obter certa corrente média, utilizando a equação:

$$
\operatorname{Im}=\frac{(I p \cdot t p+I b . t b)}{T}
$$

\subsection{Determinação da variabilidade}

Com o objetivo de investigar como os diferentes níveis de corrente de soldagem afetam a variabilidade da geometria e da diluição dos cordões de solda realizados com os diferentes modos de transferência metálica, foram executados dois conjuntos de ensaios (soldas), um com arame maciço e outro com arame tubular utilizando as condições de soldagem indicadas nas Tabelas 1 e 2 .

Para estimar a variabilidade da geometria e da diluição dos cordões de solda realizados nestes ensaios foram definidas como respostas a serem analisadas a penetração (P), a convexidade (C) e a diluição (D). Para obter estas respostas foram retiradas cinco amostras de cada cordão, por cortes transversais espaçados em $10 \mathrm{~mm}$ e igualmente distribuídos em relação ao centro do cordão como indicado na Figura 2.

Nestas amostras foram realizados ensaios macrográficos. As macrografias resultantes destes ensaios foram fotografadas. As fotografias foram analisadas utilizando o software de processamento e análise de imagens Image Tool. Nas fotografias foram medidas a largura, o reforço, a penetração, a área de reforço e a área de penetração de cada uma das amostras, na forma indicada na Figura 3.

Tabela 1. Soldas realizadas com corrente constante.

\begin{tabular}{ccccc}
\hline $\mathbf{I m}(\mathbf{A})$ & Transferência & $\mathbf{V a}(\mathbf{m} / \mathbf{m i n})$ & Uaj (V) & DBCP ( $\mathbf{m m})$ \\
$100(85)$ & Curto-circuito & 2,4 & $16(19)$ & 12 \\
$140(110)$ & & 3,2 & $17(19)$ & 12 \\
$180(140)$ & & 4,3 & $18(19)$ & 12 \\
$280(230)$ & \multirow{2}{*}{ Goticular } & 8,5 & 33 & 16 \\
$320(250)$ & & 9,5 & 35 & 16 \\
$340(280)$ & & 10,0 & 36 & 16 \\
\hline
\end{tabular}

Nota: Valores entre parênteses são referentes ao arame tubular. 
Tabela 2. Soldas realizadas com corrente pulsada.

\begin{tabular}{ccccc}
\hline Im (A) & Transferência & Va (m/min) & Ip* (A) & DBCP (mm) \\
100 & Pulsado 1 & $3,0(3,5)$ & 280 & 16 \\
140 & & $4,0(5,0)$ & 280 & 16 \\
180 & & $5,0(6,5)$ & 280 & 16 \\
100 & Pulsado 2 & $3,0(3,5)$ & 350 & 16 \\
140 & & $4,0(5,0)$ & 350 & 16 \\
180 & & $5,0(6,5)$ & 350 & 16 \\
\hline
\end{tabular}

Notas: Valores entre parênteses são referentes ao arame tubular.

* As duas ondas pulsadas se diferenciaram, principalmente, pela corrente de pulso.
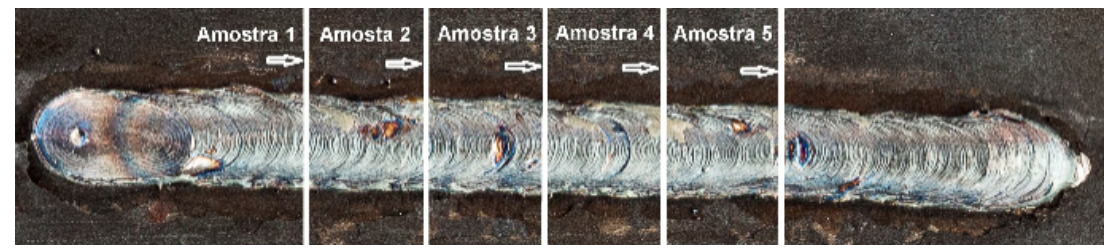

Figura 2. Localização dos cortes, que correspondem a cada uma das 5 seções preparadas metalograficamente.

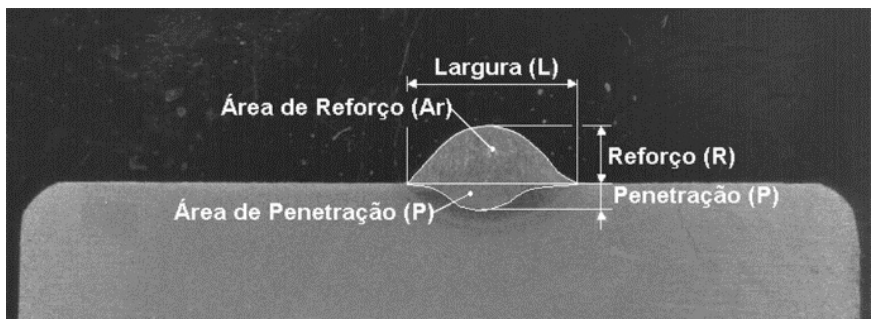

Figura 3. Forma de medição dos parâmetros geométricos.

Depois de realizadas as medições foram calculadas a diluição e a convexidade de cada amostra.

A diluição (D) foi calculada com a área de reforço e área de penetração medidas na etapa anterior utilizando a Equação 4:

$$
\mathbf{D}=\frac{\mathbf{A p}}{\mathbf{A r}+\mathbf{A p}} \cdot 100
$$

onde Ar é a área de reforço e Ap é a área de penetração.

O índice de convexidade (C) foi calculado da forma como indicou Paiva [11], com as medidas da altura do reforço e da largura do cordão utilizando a Equação 5:

$$
\mathbf{C}=\frac{\mathbf{R}}{\mathbf{L}} \cdot 100
$$

onde L é a largura e R é a altura do reforço do cordão.

Com a finalidade de analisar a variabilidade dos cordões de solda realizados conforme as condições indicadas nas Tabelas 1 e 2, depois de obtidos os valores de penetração, convexidade e diluição das cinco amostras de cada cordão de solda, foram calculadas a média, o desvio padrão e o desvio padrão relativo. 
Comparação da Estabilidade do Arco e da Variabilidade da Geometria de Soldas Obtidas pelos Processos

MIG/MAG e Arame Tubular

\section{Resultados e Discussão}

\subsection{Determinação dos parâmetros para ocorrência de transferência estável pelo modo curto-circuito}

Nas soldas realizadas com a finalidade de encontrar parâmetros para trabalhar com corrente próxima de $100 \mathrm{~A}$, foi necessária uma velocidade de arame de $2,4 \mathrm{~m} / \mathrm{min}$, com a qual foi obtida corrente média de 101,9 A e tensão do arco de 17,8 V. De forma similar, para as correntes de soldagem próximas a 140 e $180 \mathrm{~A}$ foram necessárias velocidades de arame 3,2 e 4,3 m/min, respectivamente, e a tensão obtida foi de 19,9 V. Nos ensaios realizados com a finalidade de investigar a influencia da tensão e da indutância os resultados mostraram que embora para um determinado valor de tensão e velocidade de arame as soldas realizadas com os três diferentes níveis de efeito indutivo apresentassem visualmente boa regularidade na geometria do cordão o que indicaria que a indutância tem pouca influência sobre regularidade, nas soldas com menor variabilidade (desvio padrão relativo) dos picos de corrente e dos períodos de transferência metálica também ocorreram menor variabilidade da geometria e da diluição dos cordões de solda. Como mostram, por exemplo, os resultados das soldas realizadas com velocidade de arame de $2,4 \mathrm{~m} / \mathrm{min}$, tensão regulada em $18 \mathrm{~V}$ e os três níveis de efeito indutivo (20, 50 e 80 ) onde os desvios padrão da penetração foram respectivamente $20,53 \% ; 8,53 \%$ e $10,61 \%$, da convexidade foram $18,66 \% ; 6,45 \%$ e $9,20 \%$ e da diluição foram $12,63 \% ; 6,03 \%$ e $8,18 \%$ e os desvios padrão dos picos de corrente foram respectivamente 9,3\%; $9,0 \%$ e 9,3\% e da transferência metálica foram $21,1 \% ; 16,9 \%$ e $23,3 \%$. Isso indica que os parâmetros desvio padrão relativo dos picos de corrente e dos períodos de transferência metálica são eficazes e altamente sensíveis para quantificar a estabilidade da transferência metálica.

Desta forma, embora todas as soldas realizadas com velocidade de arame de $2,4 \mathrm{~m} / \mathrm{min}$ e os três valores de tensão e efeito indutivos adotados apresentem visualmente boa regularidade na geometria do cordão (vide na Figura 4) [[Q1: Q1]] as fotografias de topo destes cordões de solda), o desvio padrão relativo dos períodos de transferência metálica e dos picos de corrente (calculados com base em intervalos de tempo de $10 \mathrm{~s}$ ), para os três níveis de tensão utilizados foi menor para as soldas realizadas com efeito indutivo ajustado no valor médio da fonte $(\mathrm{Ks}=\mathrm{Kd}=50)$ como mostram os valores destacados em negrito na Tabela 3 e os trechos dos oscilogramas de corrente e tensão apresentados nas Figuras 5, 6 e 7.

Com base nos dados gerados nos ensaios de iso-consumo com efeito indutivo $\mathrm{Ks}=\mathrm{Kd}$ ajustado em 50 foi plotada a relação que existe entre a frequência de transferência e a tensão ajustada na fonte de energia (Figuras 8, 9 e 10). Isto permitiu identificar a faixa de correntes em que ocorre transferência por curto-circuito, transferência mista (curto-circuito e globular) e transferência globular. Na Figura 8, que corresponde aos ensaios com velocidade de arame de $2,4 \mathrm{~m} / \mathrm{min}$, os limites dessas faixas são facilmente identificáveis: na transferência globular, a taxa de transferência é muito pequena (menor que 5 gotas/s), enquanto que para a transferência por curto-circuito é muito maior (mais de 15 gotas/s). Há uma faixa com taxas intermediárias, que corresponde à transferência mista (globular e curto-circuito).
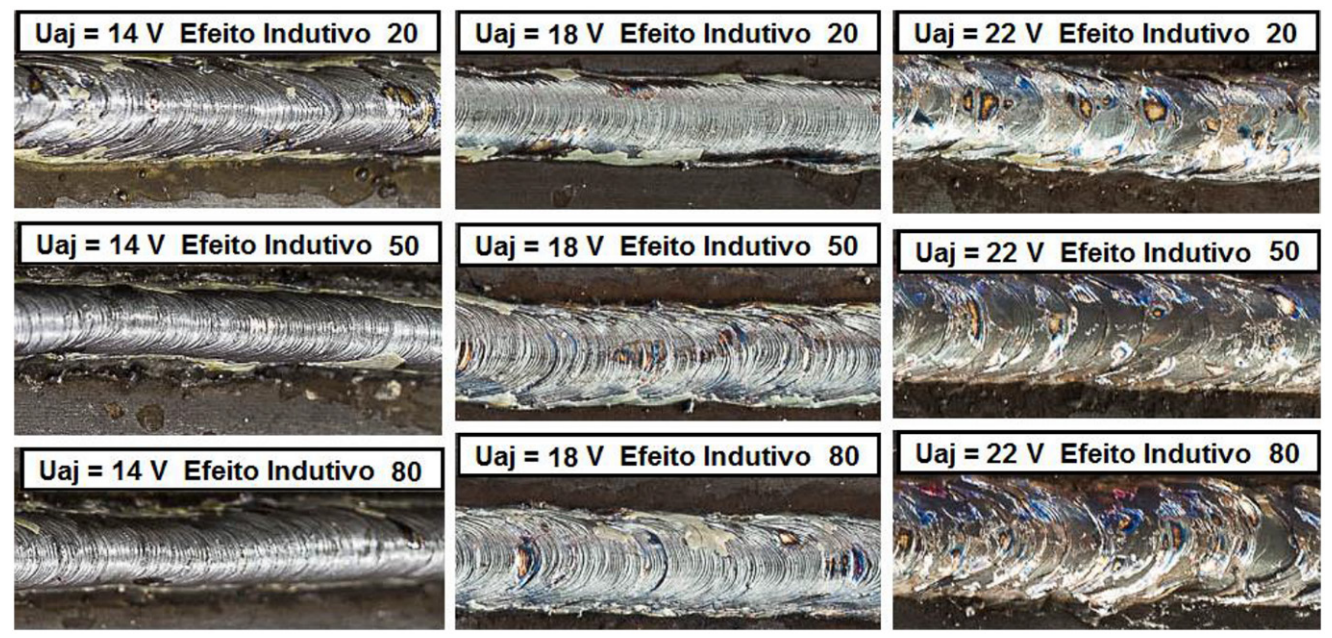

Figura 4. Fotos das soldas dos ensaios de tensão versus efeito indutivo com $\mathrm{Va}=2,4 \mathrm{~m} / \mathrm{min}$. 
Tabela 3. Soldas obtidas com Va = 2,4 m/min, variando a tensão e o efeito indutivo.

\begin{tabular}{cccc}
\hline $\begin{array}{c}\text { Uaj } \\
\text { (V) }\end{array}$ & $\begin{array}{c}\text { Efeito } \\
\text { Indutivo }\end{array}$ & \multicolumn{2}{c}{ Desvios Padrão Relativos (\%) } \\
Ip T \\
\multirow{2}{*}{14} & $\mathbf{2 0}$ & $\mathbf{2 8 , 3}$ & $\mathbf{3 4 , 9}$ \\
& $\mathbf{5 0}$ & $\mathbf{4 , 4}$ & $\mathbf{2 , 3}$ \\
& 80 & 47,0 & 16,0 \\
18 & 20 & 9,3 & 21,1 \\
& $\mathbf{5 0}$ & $\mathbf{9 , 0}$ & $\mathbf{1 6 , 9}$ \\
& 80 & 9,3 & 23,3 \\
22 & 20 & 17,9 & 44,6 \\
& $\mathbf{5 0}$ & $\mathbf{5 , 7}$ & $\mathbf{1 7 , 8}$ \\
& 80 & 6,9 & 25,4 \\
\hline
\end{tabular}

Nota: Ip = pico de corrente e $T$ = período de transferência.
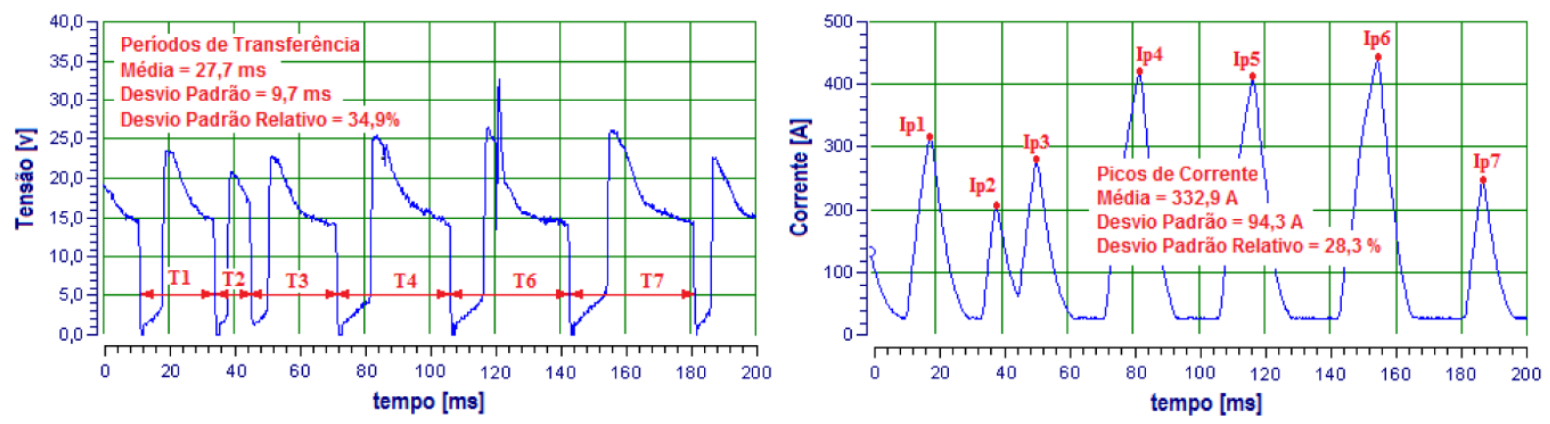

Figura 5. Oscilogramas da solda realizadas com Va =2,4 m/min, Uaj em $14 \mathrm{~V}$ e efeito indutivo 20.
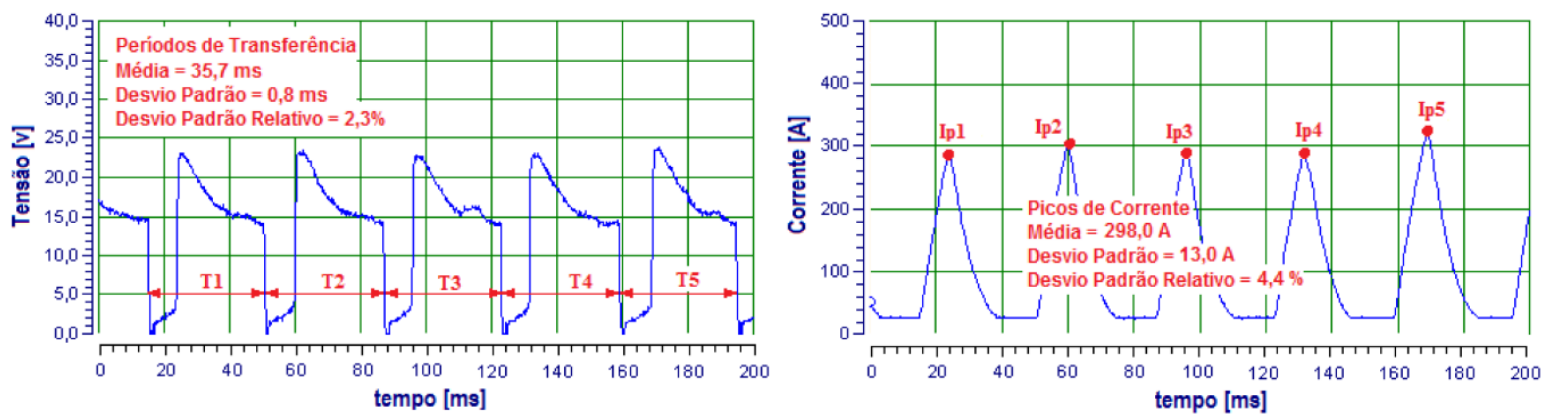

Figura 6. Oscilogramas da solda realizada com $\mathrm{Va}=2,4 \mathrm{~m} / \mathrm{min}$, Uaj em $14 \mathrm{~V}$ e efeito indutivo 50.
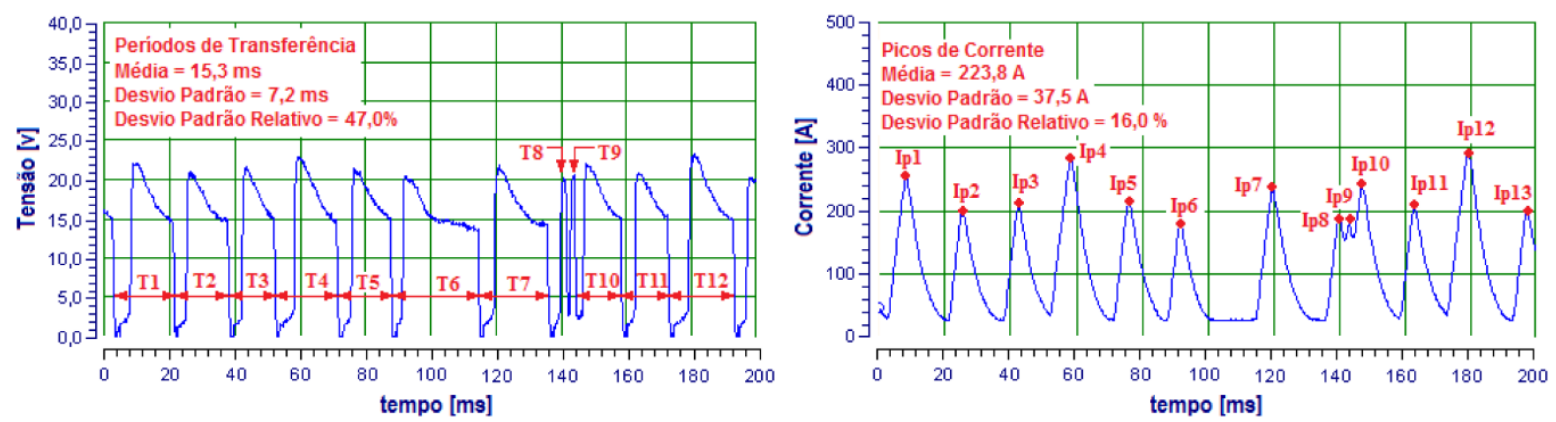

Figura 7. Oscilograma da solda realizada com Va =2,4 m/min, Uaj em $14 \mathrm{~V}$ e efeito indutivo 80. 
Nos gráficos elaborados para maiores velocidades de arame, torna-se mais difícil identificar a faixa de transferência mista. Para $\mathrm{Va}=3,2 \mathrm{~m} / \mathrm{min}$ parece estar entre 23 e $27 \mathrm{~V}$. Para $\mathrm{Va}=4,3 \mathrm{~m} / \mathrm{min}$ a faixa começa com $27 \mathrm{~V}$ e seu limite superior parece ultrapassar $30 \mathrm{~V}$. Os modos de transferência foram conferidos, adicionalmente, nos oscilogramas de corrente e tensão. Por exemplo, nos oscilogramas das Figuras 11, 12, 13 e 14 é possível verificar que nas soldas realizadas com velocidade de soldagem de $300 \mathrm{~mm} / \mathrm{min}$, velocidade de arame de $3,2 \mathrm{~m} / \mathrm{min}$ e DBCP $=12 \mathrm{~mm}$, ao utilizar Uaj de 12, 17 e $19 \mathrm{~V}$ a transferência foi por curto-circuito, com uma melhor condição de estabilidade para Uaj = $17 \mathrm{~V}$. Ao soldar com uma tensão maior, Uaj= 29 V (Figura 14) a transferência foi mista (foi globular a maior parte do tempo, com um curto-circuito ocorrendo no tempo $t=1 \mathrm{~s}$ ).

Além disso, há que salientar que o valor de tensão ajustada (Uaj) que resultou na maior estabilidade aumentou com a velocidade do arame: para $\mathrm{Va}=2,4 \mathrm{~m} / \mathrm{min}$ a melhor condição foi Uaj= $16 \mathrm{~V}$, para $\mathrm{Va}=3,2 \mathrm{~m} / \mathrm{min}$ a melhor condição foi Uaj= $17 \mathrm{~V}$ e para $\mathrm{Va}=4,3 \mathrm{~m} / \mathrm{min} \mathrm{Uaj}=18 \mathrm{~V}$. Por outra parte, o valor de Uaj para maior estabilidade independe da velocidade de soldagem.

\subsection{Determinação dos parâmetros para ocorrência de transferência estável pelo modo goticular}

Como já mencionado neste trabalho, com a finalidade de determinar as tensões para as quais ocorre transferência goticular para os níveis de corrente 280, 320 e 340 A, foram realizados ensaios de iso-consumo com velocidades de arame de 8,$5 ; 9,5$ e $10 \mathrm{~m} / \mathrm{min}$. A tensão foi aumentada em degraus de $1 \mathrm{~V}$, até conseguir transferência goticular. Uma das formas de verificar a ocorrência de transferência goticular é mediante o processamento dos oscilogramas, assim utilizando o valor do tempo de curto-circuito (duração média do curto-circuito, valores fornecidos pelo SAP) foi possível inferir sobre a ocorrência de transferência goticular, pois neste tipo de transferência não há curtos-circuitos, ou seja, o valor do tempo de duração média do curto-circuito é nulo. Desta maneira, para o nível de corrente $280 \mathrm{~A}$ (que foi obtida com velocidade de arame de $8,5 \mathrm{~m} / \mathrm{min}$ ) a transferência pelo modo goticular ocorreu com tensão ajustada em $33 \mathrm{~V}$, como mostram os valores destacados em negrito na Tabela 4, confirmados nos oscilogramas da Figura 15. Da mesma forma, para o nível de corrente $320 \mathrm{~A}$ (obtida com velocidade de arame de 9,5 m/min) a transferência pelo modo goticular ocorreu com tensão ajustada em $35 \mathrm{~V}$ e para o nível de corrente de 340A (obtida com velocidade de arame de $10 \mathrm{~m} / \mathrm{min}$ ) a transferência pelo modo goticular ocorreu com tensão de $36 \mathrm{~V}$.

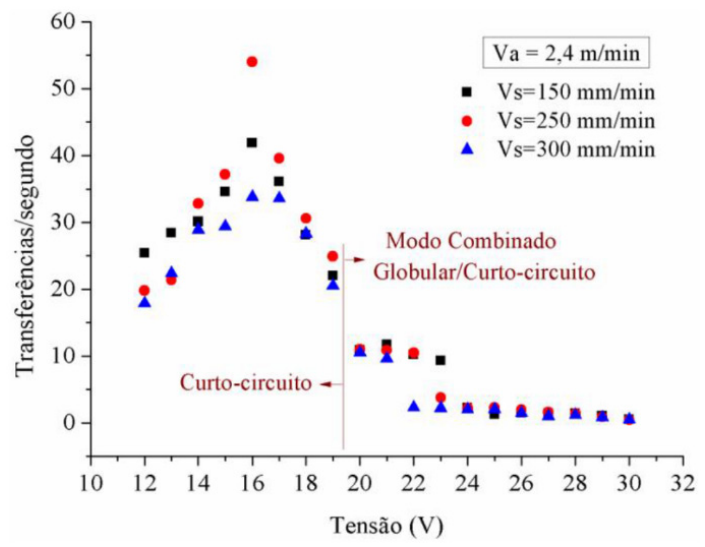

Figura 8. Variação da frequência de transferência metálica com a tensão ajustada, para $V a=2,4 \mathrm{~m} / \mathrm{min}$.

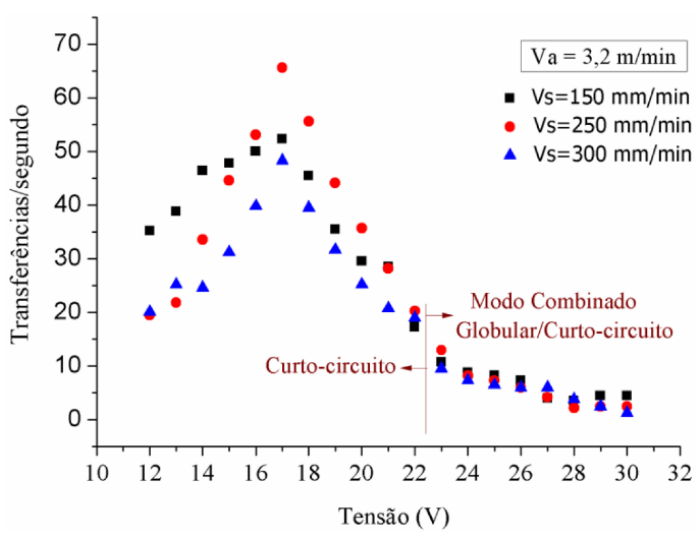

Figura 9. Variação da frequência de transferência metálica com a tensão ajustada, para $V a=3,2 \mathrm{~m} / \mathrm{min}$.

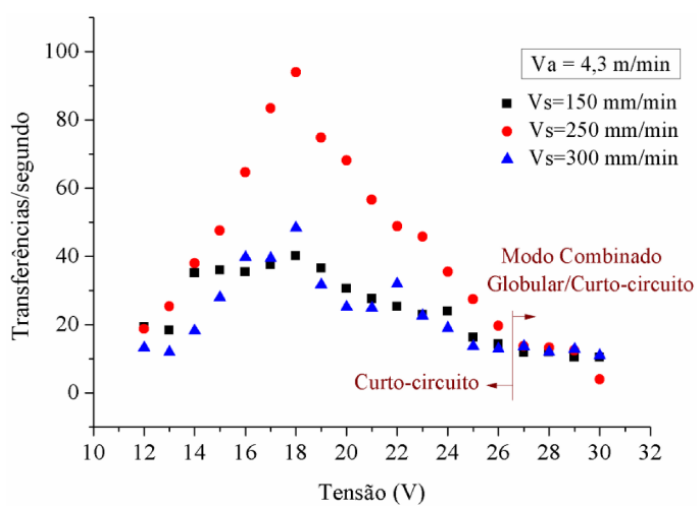

Figura 10. Variação da frequência de transferência metálica com a tensão ajustada, para $\mathrm{Va}=4,3 \mathrm{~m} / \mathrm{min}$. 

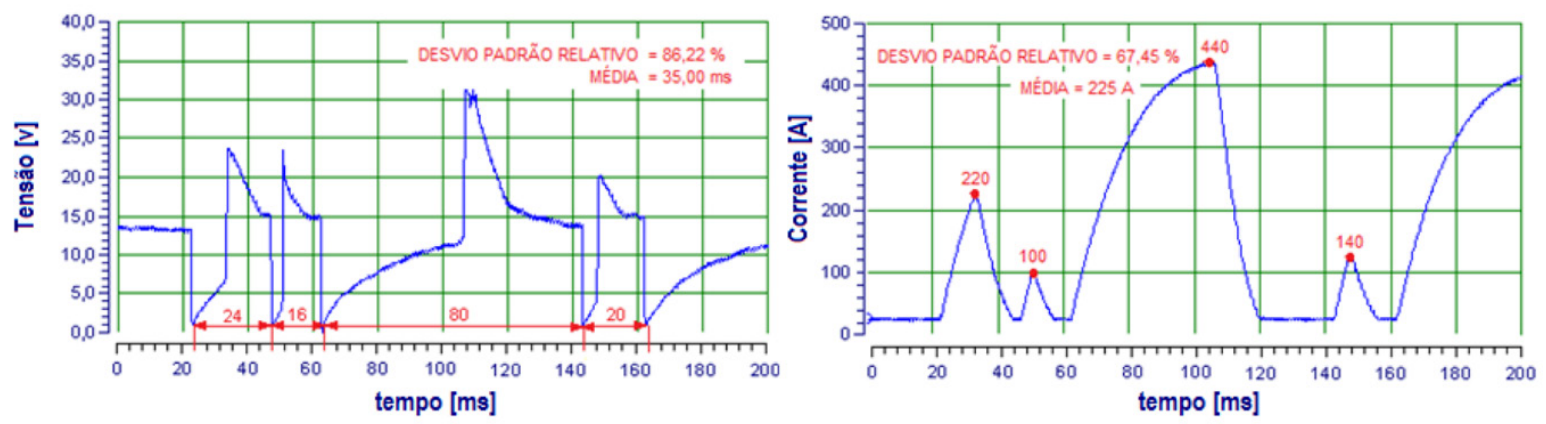

Figura 11. Oscilogramas da solda realizada com Vs $=300 \mathrm{~mm} / \mathrm{min}, \mathrm{Va}=3,2 \mathrm{~m} / \mathrm{min}$, Uaj $=12 \mathrm{~V}$ e DBCP $=12 \mathrm{~mm}$.
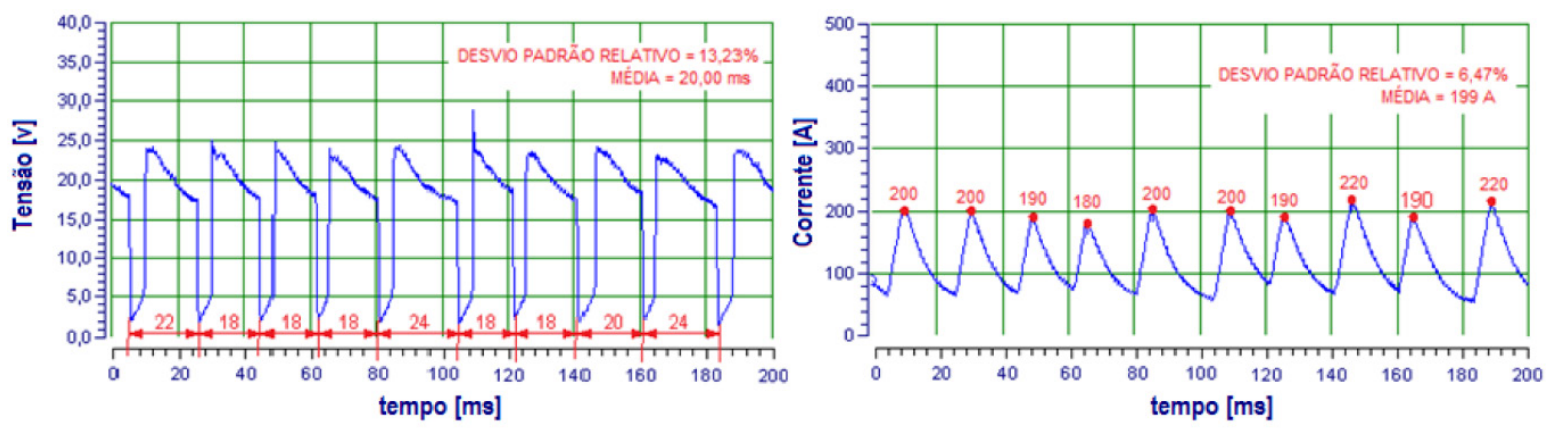

Figura 12. Oscilogramas da solda realizada com $\mathrm{Vs}=300 \mathrm{~mm} / \mathrm{min}, \mathrm{Va}=3,2 \mathrm{~m} / \mathrm{min}$, Uaj $=17 \mathrm{~V}$ e $\mathrm{DBCP}=12 \mathrm{~mm}$.
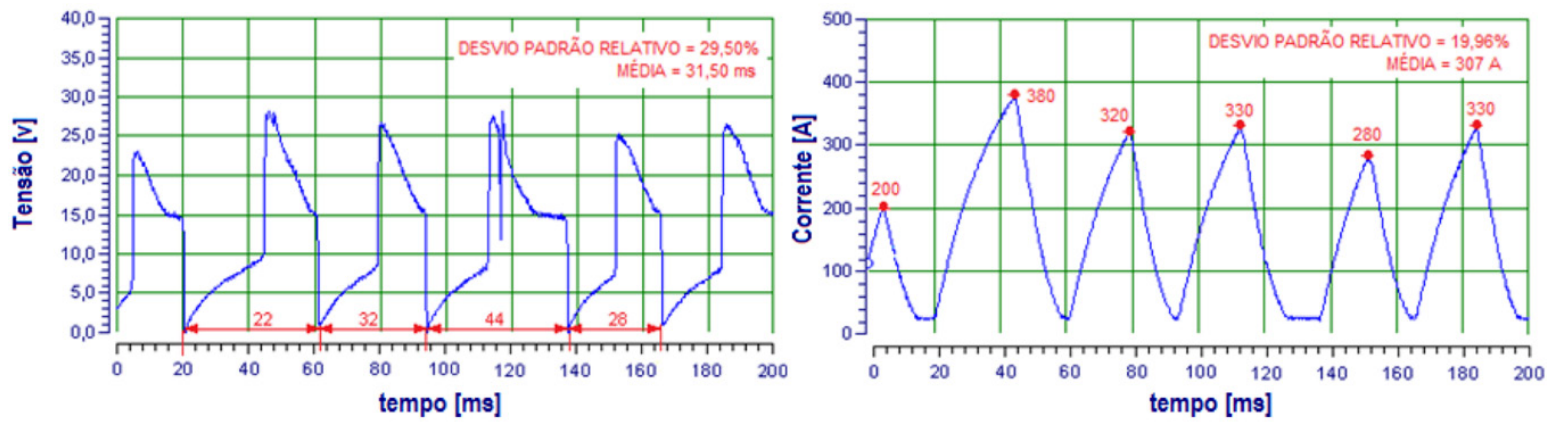

Figura 13. Oscilogramas da solda realizada com $V s=300 \mathrm{~mm} / \mathrm{min}, \mathrm{Va}=3,2 \mathrm{~m} / \mathrm{min}$, Uaj $=19 \mathrm{~V}$ e $\mathrm{DBCP}=12 \mathrm{~mm}$.
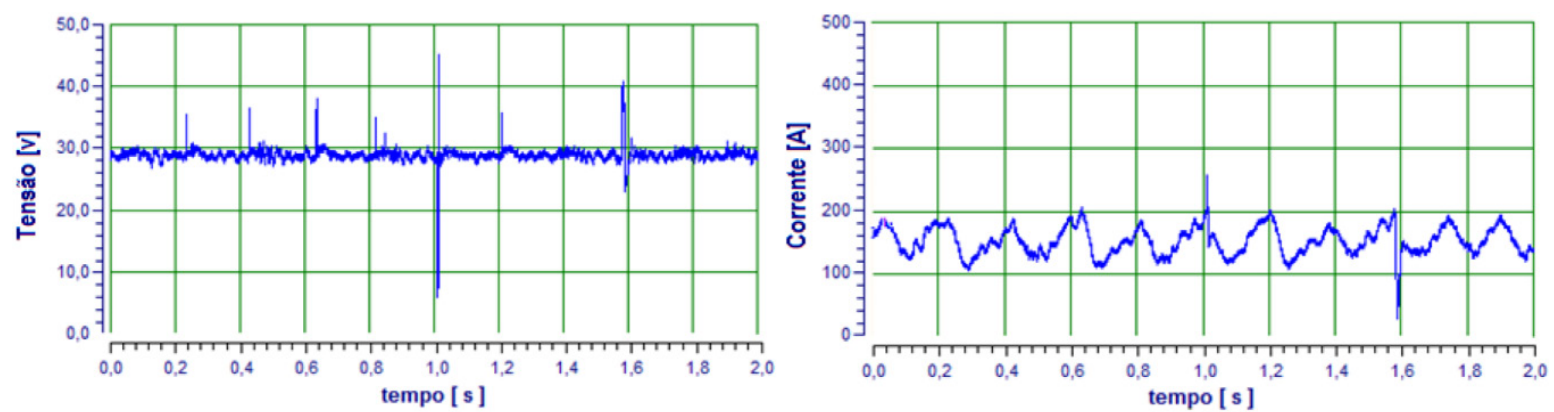

Figura 14. Oscilogramas da solda realizada com Vs=300 mm/min, Va =3,2 m/min, Uaj = 29 V e DBCP = $12 \mathrm{~mm}$. 
Comparação da Estabilidade do Arco e da Variabilidade da Geometria de Soldas Obtidas pelos Processos MIG/MAG e Arame Tubular

Tabela 4. Ensaios de iso-consumo com velocidade de arame de $8,5 \mathrm{~m} / \mathrm{min}$.

\begin{tabular}{cccc}
\hline Uaj (V) & Im (A) & Um (V) & Tempo de Curto-Circuito (ms) \\
31 & 269,7 & 30,9 & 0,8 \\
32 & 274,5 & 31,9 & 0,4 \\
33 & $\mathbf{2 8 2 , 0}$ & $\mathbf{3 2 , 9}$ & $\mathbf{0 , 0}$ \\
34 & 285,7 & 33,9 & 0,0 \\
35 & 288,9 & 34,9 & 0,0 \\
\hline
\end{tabular}

Nota: Uaj = tensão ajustada, Im = corrente média, Um = tensão média.

\subsection{Determinação dos parâmetros para ocorrência de transferência estável pelo modo pulsado}

Na Tabela 5 são apresentados os valores (calculados utilizando o método descrito no item 2.4) dos parâmetros para obter uma transferência metálica estável ao soldar pelo modo pulsado.

\subsection{Comparação da variabilidade}

A fim de comparar a variabilidade das soldas realizadas com as condições indicadas nas Tabelas 1 e 2 foram graficados os valores do desvio padrão relativo (DPR) da penetração, da convexidade e da diluição. Deste modo o gráfico da Figura 16a mostra que as variabilidades da penetração das soldas realizadas com arame tubular e modos curto-circuito e goticular (DPR de 15 a $25 \%$ e 15 a $27,5 \%$ respectivamente), foram maiores do que nas soldas realizadas com arame maciço (DPR de 2,5 a 17,5\% e 2,5 a 22,5\% respectivamente). No gráfico da Figura 16b que apresenta o DPR da penetração das soldas realizadas pelo modo pulsado observa-se que as variabilidades da penetração das soldas realizadas com arame tubular, valores de DPR na faixa de 15 a $25 \%$ para o pulsado 1 (corrente de pico $280 \mathrm{~A}$ ) e de 30 a $35 \%$ para o pulsado 2 (corrente de pico $350 \mathrm{~A}$ ), foram muito maiores do que nas soldas realizadas com arame maciço, com DPR de 5 a $10 \%$ para o pulsado 1 e de 2,5 a $17,5 \%$ para o pulsado 2 .

Tabela 5. Valores das variáveis para transferência pelo modo pulsado.

\begin{tabular}{|c|c|c|c|c|c|c|}
\hline Va (m/min) & $\operatorname{Im}(A)$ & $\mathbf{T}(\mathrm{ms})$ & Ip (A) & Ip (ms) & Ib (A) & tb (ms) \\
\hline $3,0(3,5)$ & 100 & $28(24)$ & $\begin{array}{l}280 \\
350\end{array}$ & $\begin{array}{l}6,5 \\
4,0\end{array}$ & $\begin{array}{l}46(33) \\
57(50)\end{array}$ & $\begin{array}{l}21,5(17,5) \\
24,0(20,0)\end{array}$ \\
\hline $4,0(5,0)$ & 140 & $21(17)$ & $\begin{array}{l}280 \\
350\end{array}$ & $\begin{array}{l}6,5 \\
4,0\end{array}$ & $\begin{array}{l}77(53) \\
88(75)\end{array}$ & $\begin{array}{l}14,5(10,5) \\
17,0(13,0)\end{array}$ \\
\hline $5,0(6,5)$ & 180 & $17(13)$ & $\begin{array}{l}280 \\
350\end{array}$ & $\begin{array}{l}6,5 \\
4,0\end{array}$ & $\begin{array}{l}118(80) \\
112(104)\end{array}$ & $\begin{array}{l}10,5(6,5) \\
13,0(9,0)\end{array}$ \\
\hline
\end{tabular}

Nota: Valores entre parênteses são referentes ao arame tubular.
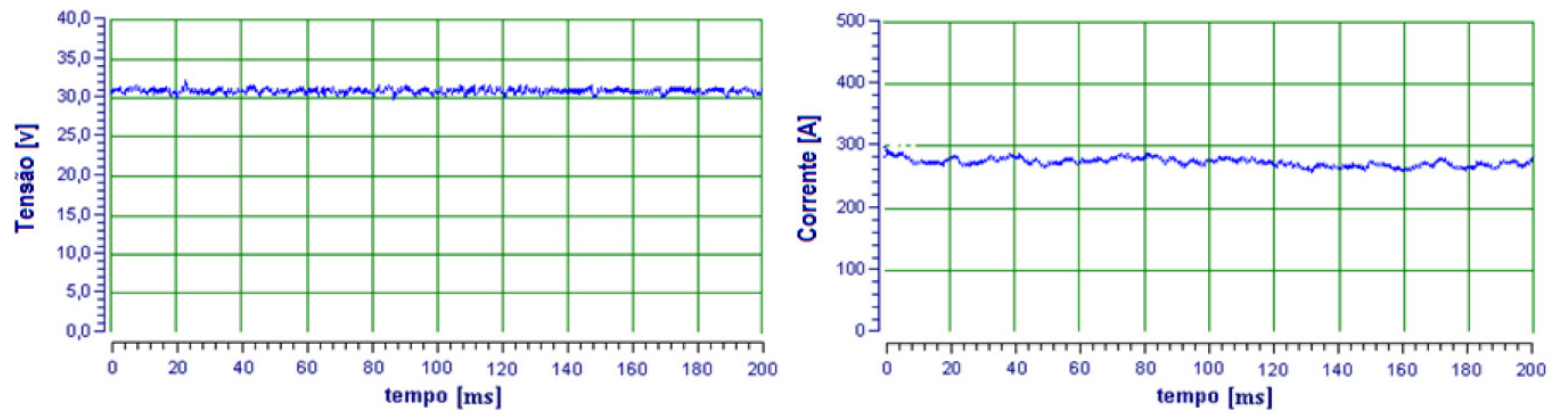

Figura 15. Ensaio realizado com $\mathrm{Va}=8,5 \mathrm{~m} / \mathrm{min}$ e tensão justada $33 \mathrm{~V}$. 
Da mesma maneira o gráfico da Figura 17a mostra que a variabilidade da convexidade das soldas realizadas por curto-circuito e arame maciço (DPR de 5 a 20\%) foi maior do que nas soldas realizadas com arame tubular (DPR de 7,5 a 12,5\%) e mostra ainda que a variabilidade da convexidade das soldas realizadas pelo modo goticular e arame tubular (DPR de 5 a 17,5\%) foi maior do que nas soldas realizadas com arame maciço (DPR de 2,5 a 7,5\%). No gráfico da Figura 17b observa-se que as variabilidades da convexidade das soldas realizadas pelo modo pulsado e arame tubular, com DPR de 17,5 a $22,5 \%$ para o pulsado 1 e DPR de 30 a $35 \%$ para o pulsado 2 foram muito maiores do que nas soldas realizadas com arame maciço com DPR de 5 a $10 \%$ para o pulsado 1 e DPR de 2,5 a $17,5 \%$ para o pulsado 2 .

Ainda o gráfico da Figura 18a mostra que a variabilidade na diluição das soldas realizadas com arame maciço e modo curto-circuito (DPR de 2,5 a 25\%), foi maior do que nas soldas realizadas pelo mesmo modo e com arame tubular (DPR de 7,5 a 17,5\%). Neste gráfico observa-se também que a faixa de variabilidade da diluição das soldas realizadas pelo modo goticular e arame maciço (DPR de 5 a 27,5\%) foi maior do que nas soldas realizadas pelo mesmo modo e com arame tubular (DPR de 17,5 a 25\%). Finalmente no gráfico da Figura 18b observa-se que as variabilidades na diluição das soldas realizadas pelo modo pulsado e arame tubular, com DPR de 17,5 a $35 \%$ para o pulsado 1 e DPR de 27,5 a $37,5 \%$ para o pulsado 2 foram muito maiores do que nas soldas realizadas com arame maciço com DPR de 10 a 15\% para o pulsado 1 e DPR de 2,5 a 12,5\% para o pulsado 2 .

Além disso, há que salientar que as variabilidades da penetração, da convexidade e da diluição das soldas realizadas pelo modo pulsado e arame tubular foram maiores do que as das soldas realizadas pelo mesmo modo, porém com arame maciço, e também as variabilidades da penetração, da convexidade e da diluição das soldas realizadas com arame tubular e modo pulsado 2 (corrente de pico $350 \mathrm{~A}$ ) foram maiores do que das soldas realizadas com arame tubular e modo pulsado 1 (corrente de pico $280 \mathrm{~A}$ ).
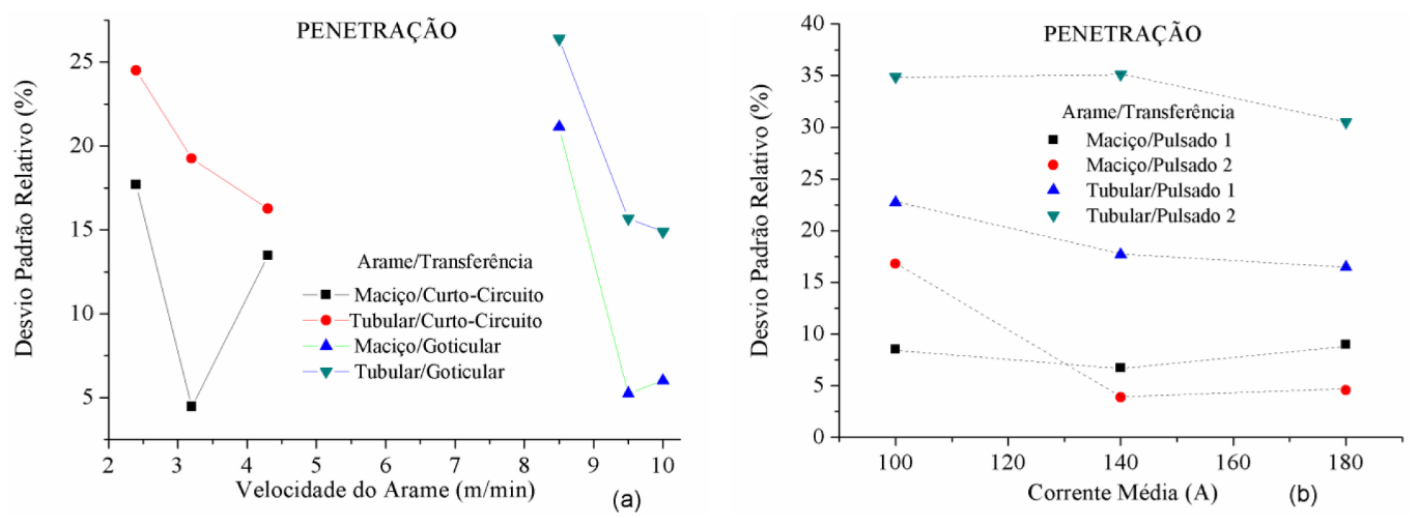

Figura 16. Desvio padrão relativo da penetração das soldas realizadas conforme as condições das Tabelas 1 e 2.
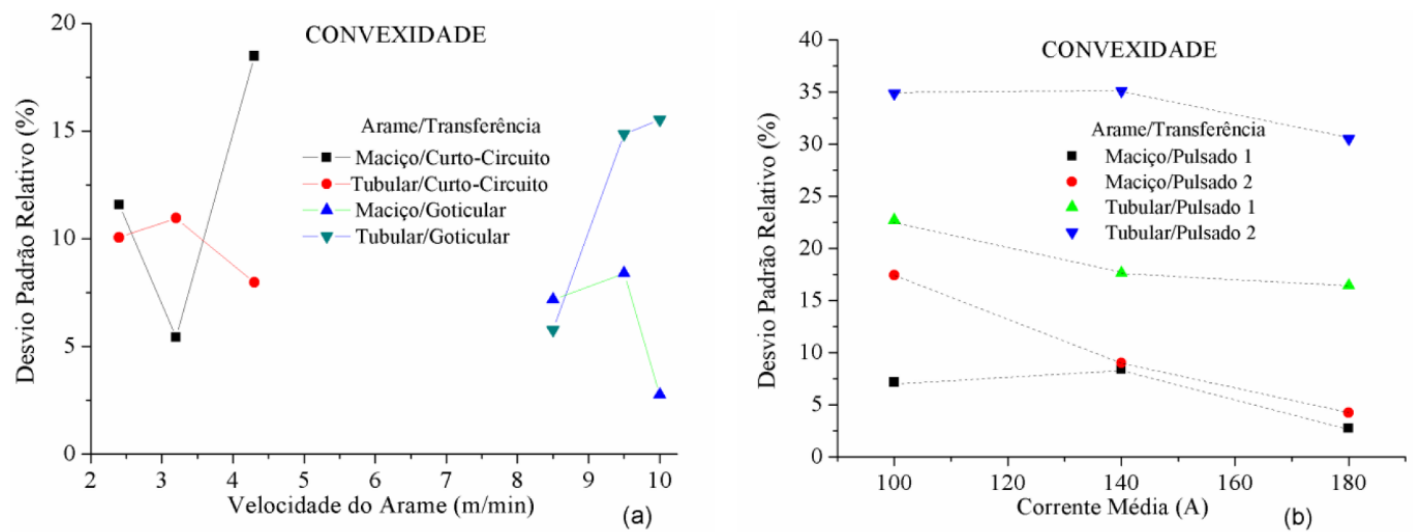

Figura 17. Desvio padrão relativo da convexidade das soldas realizadas conforme as condições das Tabelas 1 e 2 . 

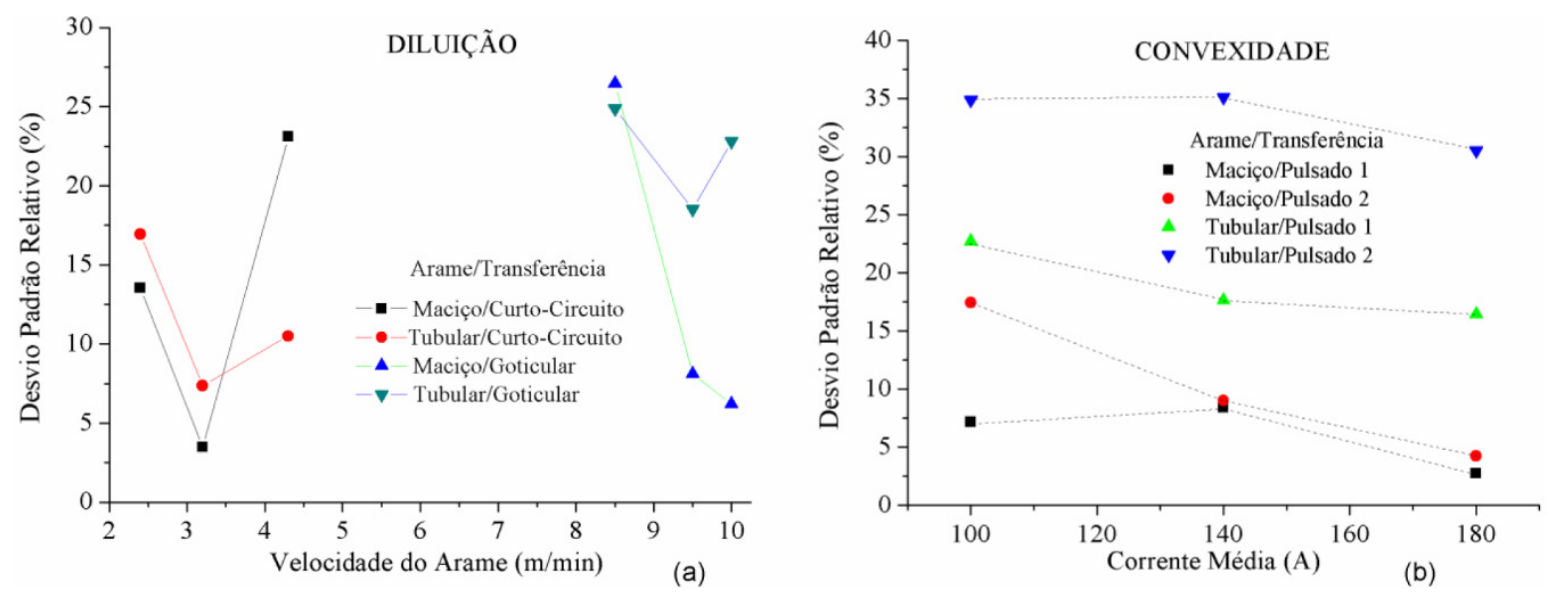

Figura 18. Desvio padrão relativo diluição das soldas realizadas conforme as condições das Tabelas 1 e 2 .

\section{Conclusões}

Para as condições e parâmetros de soldagem utilizados neste trabalho, pode-se concluir que:

a) Os parâmetros, desvio padrão relativo (DPR) dos períodos de transferência metálica e dos picos de corrente são eficazes e altamente sensíveis para quantificar a estabilidade do arco como mostram, por exemplo, os valores do DPR da solda realizada com Va $=2,4 \mathrm{~m} / \mathrm{min}$, $\mathrm{Uaj}=14 \mathrm{~V}$ e $\mathrm{Ks}=\mathrm{Kd}=50$ foram muito menores $(2,3 \%$ e 4,4\%, respectivamente) que aqueles para $\mathrm{Ks}=\mathrm{Kd}=20$ (34,9\% e $28,3 \%)$ e $\mathrm{Ks}=\mathrm{Kd}=80(47,0 \%$ e $16,0 \%)$ e foram confirmados pela menor variabilidade da geometria e da diluição destes cordões de solda.

b) A condição de transferência com maior regularidade e ou estabilidade para o modo curto circuito depende não só do valor da tensão ajustada como também da indutância como indicam o desvio padrão relativo (variabilidade) dos períodos de transferência metálica e dos picos de corrente, que para os três níveis de tensão utilizados foram menores para o efeito indutivo ajustado em 50 (valor médio da fonte).

c) O valor da tensão ajustada (Uaj) que determina a maior estabilidade na transferência pelo modo curtocircuito independe da velocidade de soldagem e aumenta com a velocidade do arame: para $\mathrm{Va}=2,4 \mathrm{~m} / \mathrm{min}$ a melhor condição foi Uaj $=16 \mathrm{~V}$, para $\mathrm{Va}=3,2 \mathrm{~m} / \mathrm{min}$ foi Uaj $=17 \mathrm{~V}$ e para $\mathrm{Va}=4,3 \mathrm{~m} / \mathrm{min}$ foi Uaj $=18 \mathrm{~V}$.

\section{Quanto à variabilidade da Penetração:}

d) Nas soldas realizadas com transferência por curto-circuito, com arame tubular foi maior que com arame maciço (DPR de 15 a $25 \%$ e de 2,5 a $17,5 \%$ respectivamente).

e) Nas soldas realizadas com transferência goticular, com arame tubular foi maior que com arame maciço (DPR de 15 a $27,5 \%$ e de 2,5 a $22,5 \%$ respectivamente).

f) Nas soldas realizadas com corrente pulsada, com arame tubular (DPR de 17,5 a $22,5 \%$ e de 30 a $35 \%$ ) foi muito maior que com arame maciço (DPR de 5 a $10 \%$ e de 2,5 a $17,5 \%$ ).

\section{Quanto à variabilidade da Diluição:}

g) Nas soldas realizadas com transferência por curto-circuito, foi maior com arame maciço do que com arame tubular (DPR de 2,5 a $25 \%$ e de 7,5 a $17,5 \%$, respectivamente).

h) Nas soldas realizadas com transferência goticular, foi maior com arame maciço do que com arame tubular (DPR de 5 a $27,5 \%$ e de 17,5 a $25 \%$, respectivamente).

i) Nas soldas realizadas com corrente pulsada, a variabilidade foi maior com arame tubular (DPR de 17,5 a 35\% e de 27,5 a $37,5 \%$ ) do que com arame maciço (DPR de 10 a 15 e de 2,5 a $12,5 \%$ ). 


\section{Quanto à variabilidade da convexidade:}

j) Nas soldas realizadas por curto-circuito, a variabilidade com arame maciço (DPR de 5 a 20\%) foi maior do que com arame tubular (DPR de 7,5 a 12,5\%).

k) Nas soldas realizadas com transferência goticular, a variabilidade foi maior com arame tubular (DPR de 5 a 17,5\%) do que com arame maciço (DPR de 2,5 a 7,5\%).

I) Nas soldas realizadas com corrente pulsada, a variabilidade foi muito maior com arame tubular (DPR de 17,5 a $22,5 \%$ e de 30 a $35 \%$ ) do que com arame maciço (DPR de 2,5 a $7,5 \%$ e de 5 a $17,5 \%$ para o pulsado 2 ).

\section{Agradecimentos}

Os autores gostariam de agradecer ao professor DR. Aleir Antonio Fontana de Paris pela disponibilização do laboratório de soldagem e materiais para realização deste trabalho e a coordenação de pessoal de nível superior (CAPES) pela bolsa de doutorado de Romário M. U. Nogueira.

\section{Referências}

[1] Montgomery, D. C. Introdução ao controle estatistico da qualidade. Rio de Janeiro: LTC - Livros Técnicos e Científicos Editora; 2004.

[2] Resende GM, Liskévych O, Vilarinho LO, Scotti A. Um critério para determinar a regulagem da tensão em soldagem MIG/MAG por curto-circuito. Soldagem \& Inspeção. 2011;16(2):98-103.

[3] Mita T, Sakabe A, Yokoo T. Quantitative estimatives of arc stability for $\mathrm{CO} 2$ gas shielded arc welding. Welding Internacional. 1988;2(2):152-159. http://dx.doi.org/10.1080/09507118809447460.

[4] Baixo CE, Dutra JC. O estudo da transferência metálica no processo de soldagem MIG/MAG. Revista Soldagem e Materiais. 1990;21:32-36.

[5] Kang MJ, Rhee S. The statistical models for estimating the amount of spatter in the short circuit transfer mode of GMAW. Welding Journal. 2001;80(1):1s-8s.

[6] Den Ouden G, Hermans M. Process behavior and stability in short circuit gas metal arc welding. Welding Journal. 1999;78(4):137141.
[7] Souza D, Rossi ML, Keocheguerians F, Nascimento VC, Vilarinho LO, Scotti A. Influência da regulagem de parâmetros de soldagem sobre a estabilidade do processo MIG/MAG operando em curto-circuito. Soldagem \& Inspeção. 2011;16(1):22-32. http:// dx.doi.org/10.1590/S0104-92242011000100004.

[8] Subramanian S, White DR, Jones JE, Lyons DW. Droplet transfer in pulsed gas metal arc welding of aluminum. Welding Journal. 1998;11:459-465.

[9] Kim YS, Eagar TW. Analisys of metal transfer in gas metal arc welding. Welding Journal. 1993;74(7)

[10] Motta, M. F. Aplicação do processo mig/mag pulsado com duplo arame e potenciais isolados em soldagens de revestimento [tese de doutorado]. Florianópolis: Universidade Federal de Santa Catarina; 2002.

[11] Paiva EJ, Rodrigues LO, Costa SC, Paiva AP, Balestrassi PP. Otimização do processo de soldagem FCAW usando o erro quadrático médio multivariado. Soldagem \& Inspeção. 2010;15(1):31-40. http:// dx.doi.org/10.1590/S0104-92242010000100005. 